DOI: 10.17707/AgricultForest.62.4.25

\author{
Yusuf DOGAN, \\ Enver KENDAL, Erol ORAL ${ }^{1}$
}

\title{
IDENTIFYING OF RELATIONSHIP BETWEEN TRAITS AND GRAIN YIELD IN SPRING BARLEY BY GGE BIPLOT ANALYSIS
}

\begin{abstract}
SUMMARY
Grain yield is very important and complicated trait in spring barley breeding and rely upon combination varied plant traits (agronomic and quality). For this reason, a real barley breeding program necessaries an appropriate mentality of the relationships between grain yield and traits. The aim of study was evaluate the relationship of grain yield and other traits of 25 spring barley genotypes in one location during two years by GGE Biplot analysis. The experiments were performed according to a complete randomized block design with three replications. Factors (G, GE, and GEI) were found to be highly significant $(\mathrm{P}<0.01)$ for grain yield. GGE Biplot indicated that three group were occurred among traits, first group (thousand grain weight, protein content, crude cellulose and cold damage), second group (hectoliter weight, lodging, plant height and heading time), third group (grain yield and seed humidity). Moreover, the study showed that negative correlation was found between grain yield and traits without seed humidity. The results of AMMI model and GGE Biplot indicated that G12, G13, G16 and G18 is proper for grain yield, G2, G6, G19 and G1 desirable origin for quality and other agronomic traits to select for advance stage and use in barley breeding program.
\end{abstract}

Keywords: Spring Barley; GGE biplot; Yield; Traits, Correlation

\section{INTRODUCTION}

The considerable variation in crop circumstances, because of climatic conditions and different soil constituents, cause large annual variations in yield performance of crops. This is mainly because of low heritability of yield as a typical quantitative trait. Thus, grain yield could be affected by not only genotype, but also by environment as well by and genotype $\times$ environment interaction (Mortavazian et al 2014).

Barley (Hordeum vulgare L.) is the second important cereal crop of Turkey and accounts for about 25\% of the total cereal production (SAP 2010). In South-Eastern Anatolia, barley has been cultivated for many years and has a significant role. It is also grown mainly on rainfall conditions, but genotype $\times$ environment interaction (GEI) restricts the progress in yield improvement under

\footnotetext{
1 Yusuf Dogan, Enver Kendal corresponding author: enver21_1@hotmail.com), Erol Oral, Department of Seed Production, Kiz1ltepe Vocational Training High School, Artuklu University, 21500, Kiz1ltepe , Mardin, TURKEY

Notes: The authors declare that they have no conflicts of interest. Authorship Form signed online.
} 
rainfed and unpredictable climatic conditions. Thus, experimental research needs to be carried out over multiple environment trials in order to identify and analyse the major factors that are responsible for genotype adaptation and final selection (Kilic 2014).

The yield of each variety in any environment is a sum of environment (E) main effect, genotype (G) main effect and genotype by environment interaction (GE or GEI) (Farshadfar et al 2013). Farmers need varieties that show high performance in terms of yield and other essential agronomic traits.

Modern barley breeding is largely directed towards the development of genotypes characterized with increased yield potential, wide adaptation and high responses to agronomic inputs (Przuli et al 2014). Some agronomic and technological traits such as lodging (LOG), plant height (PH), thousand-kernel weight (TKW), hectoliter mass (HM) and grain protein content (GPC) have significant influence on barley grain yield and quality.

Different statistical analysis, such as correlation, path coefficient and principal component analysis (PCA) can be used to reveal associations between yield and other agronomic traits. The impact of AMMI and GGE Biplot methods has been clearly showed by different researchers using multi-environment. This methods; provide the correlative size and significant effects of GEI and its interaction (Asfaw et al 2009), This method enables better understanding of genotypes performance over several environments, and selection of stable and high yielding genotypes (Mirosavlievic et al 2014), Also it is important for testing promising lines under across environments to estimate stability and performance (Hagos and Abay, 2013), and thus, it is useful for breeders and supporting breeding program decisions. The cultivars which are used in Southeastern Anatolia Region are different depending on sub- regions, as three main sub-regions have different conditions to cultivate barley cultivars. So it is very important to identify cultivars for specific sub-region (Kendal 2016).

The major objective of study reveal adaptation of barley genotypes using AMMI and GGE Biplot analysis to estimate the importance of GE interaction on yield, define the correlations among traits and estimate performance of genotypes and recommend lines to release in breeding program.

\section{MATERIAL AND METHODS}

The experimental material comprising twenty lines, three national and two regional varieties (Table 1) were evaluated in different growing season (Fig. 1).

The experiment was conducted in a randomized block design with four replications at two rainfall-growing seasons (during 2004-05-2005-06). The seeding rate was used 450 seeds $\mathrm{m}-2$. Plot size was $7.2 \mathrm{~m}-2(1.2 \times 6 \mathrm{~m})$ consisting of 6 rows spaced $20 \mathrm{~cm}$ apart. Sowing was done by winter stagier drill.

The fertilization rates for all plots were used $60 \mathrm{~kg} \mathrm{~N}$ ha- 1 and $60 \mathrm{~kg} P$ ha1 with sowing time and $60 \mathrm{~kg} \mathrm{~N}$ ha- 1 was applied to plots at the early stem elongation. Harvest was done using Hege 140 harvester up on $6 \mathrm{~m} 2$. The climate data of growing seasons showed in Fig. 1. 


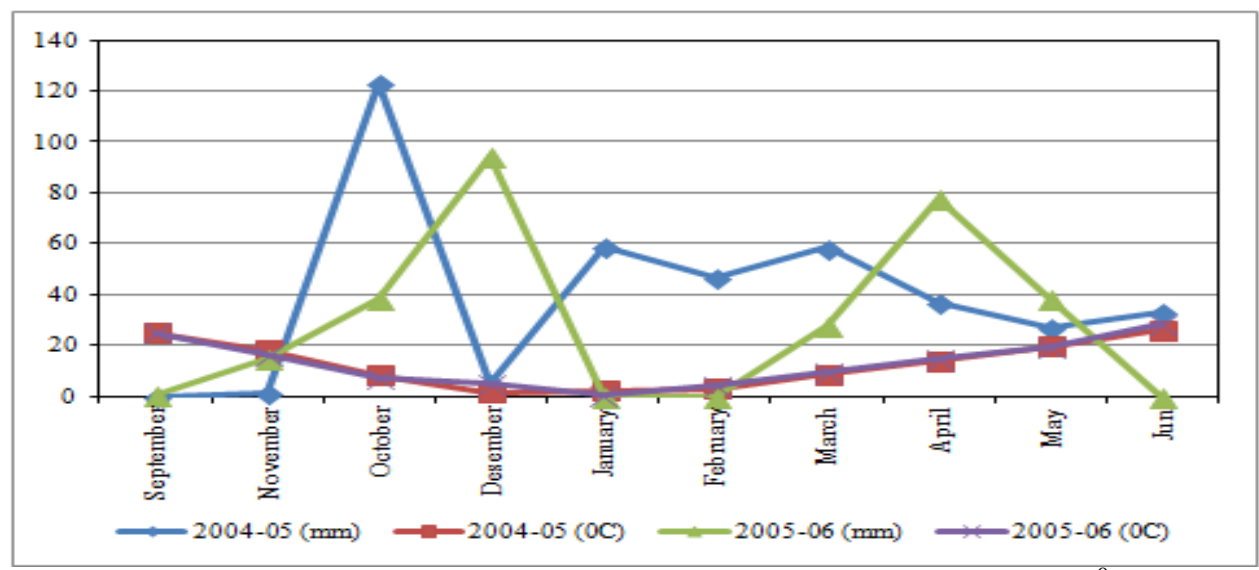

Fig.1. The average monthly rainfall $(\mathrm{mm})$ and temperature $\left({ }^{0} \mathrm{C}\right)$.

Table 1. The information's about genotypes, used in experiment.

\begin{tabular}{|c|c|}
\hline Genotype & Cultivar and /Pedigree of Province line \\
\hline$\overline{\mathrm{G} 1}$ & GOB/HUMAI10/3/MPYT169.1Y/LAUREL//... CBSS95M00804T-F-1M-2Y-3M-0Y \\
\hline G2 & GOB/HUMAI10/3/MPYT169.1Y/LAUREL//... CBSS95M00804T-F-1M-5Y-1M-0Y \\
\hline G3 & FRESA CMB94A.917-D-4M-1Y-2M-2Y-1M-0Y \\
\hline G4 & FRESA CMB94A.917-D-4M-1Y-2M-2Y-2M-0Y \\
\hline G5 & 1.1.1.ŞAHİN-91 \\
\hline$\overline{\mathrm{G} 6}$ & CEN-B/2*CALI92//ROBUST/3/LIGNEE640/DS/... ICBSS95M00871T-A-4M-1Y-1M-0Y \\
\hline G7 & GOB/HUMAI10/3/MPYT169.1Y/LAUREL//OLM... CBSS95M00804T-F-1M-10Y-1M-0Y \\
\hline G8 & CARDO/QUIBENRAS/3/ROBUST//GLORIA-B... ICBSS96WM00273T-C-1M-1Y-2M-0Y \\
\hline$\overline{\mathrm{G} 9}$ & LBIRAN/UNA80//LIGNEE640/3/BBSC/4/CH... ICBSS97Y00828T-D-4Y-1M-0Y \\
\hline G10 & 1.1.2.SUR-93 \\
\hline G11 & LENT/BLLU//PINON ICBSS97M00698T-C-2M-1Y-0M \\
\hline G12 & CEN-B/2*CALI92//MINN DESC1/3/CABUYA ICBSS96M00727T-L-1M-1Y-1M-0Y \\
\hline$\overline{\mathrm{G} 13}$ & TOCTE/QUINA/3/RHODES/CI14100//LIGNEE5...CBSS96M00842T-U-3M-2Y-1M-0Y \\
\hline$\overline{\mathrm{G} 14}$ & GLORIA-BAR/COPAL//SEN/3/BBSC/... CBSS97Y00874T-D-3Y-1M-0Y \\
\hline G15 & 1.1.3.TOKAK-157 \\
\hline G16 & CABUYA/4/GLORIABAR/COPAL//BEN.4D/3/S... CBSS97Y00819T-D-2Y-1M-0Y \\
\hline G17 & WI2269/Espe/3/WI2291/Bgs//Hml-02 ICB97-0152-0AP-13AP-0AP \\
\hline$\overline{\mathrm{G} 18}$ & Kv//Alger/Ceres.362-1-1/3/WI2269/4/Sara ICB93-0727-F7SSD-92AP-0AP \\
\hline$\overline{\mathrm{G} 19}$ & Kv//Alger/Ceres.362-1-1/3/WI2269/4/Sara ICB93-0727-F7SSD-98AP-0AP \\
\hline$\overline{\mathrm{G} 20}$ & 1.1.4.VAMIKHOCA \\
\hline G21 & Sara/4/H.spont.96-3/3/Roho//Alger/Ceres362-1-1 ICB93-0698-F7SSD-43AP-0AP \\
\hline G22 & Hashma/4/Baca’s'/3/Ac253//CI08887/CI05761 ICB97-0238-0AP-5AP-0AP \\
\hline$\overline{\mathrm{G} 23}$ & Hashma/Kataf-01 ICB97-0239-0AP-7AP-0AP \\
\hline$\overline{\mathrm{G} 24}$ & Line3229C26/3/Moroc975//WI2291/CI01387/6/Aths/... ICB97-1345-0AP-5AP-0AP \\
\hline $\mathrm{G} 25$ & 1.1.5.AKHİSAR \\
\hline
\end{tabular}


Statistical analysis: The data grain yields of twelve (25) genotypes in two growing seasons were evaluated by AMMI analysis (Gauch 1988). The AMMI and GGE biplots were used to identify the mega- environments and superior genotypes for grain yield and other traits. All statistical analyses were performed using GenStat Release 14.1 (Copyright 2011, VSN International Ltd.) and GGE biplot software programs.

The data were graphically analyzed for interpreting GE interaction using the GGE biplot software (Yan and Thinker, 2006). GGE biplot methodology is composed of the biplot concept (Gabriel 1971) and GGE concept (Yan et al 2000). The graphs generated based on (1) The AMMI 1 model showing genotype $\mathrm{x}$ environment means, (2) Mega environments "which-won-where" pattern to identify the best genotypes in each season, (3) The relationship genotype by trait, (4) "which-won-where" pattern to identify the best genotypes for traits, (5) Ranking genotypes based on traits by mean and stability, (6) Comparison of genotypes based on traits by ideal genotype.

\section{RESULTS AND DISCUSSION}

The results of AMMI Analyses in grain yield: The variance of AMMI analysis showed that as $\mathrm{p}<0.01$, the factors (genotype and environment) had significant effect on barley grain yield of twenty five genotypes tested in two growing seasons, while GEI was not significant (Table 2 and 3 ).

Table 2 The variance of AMMI analysis on grain yield of barley

\begin{tabular}{|c|c|c|c|c|c|}
\hline Source of Variance & DF & Sum of square & Mean of squares & $\begin{array}{c}\text { F } \\
\text { Ratio }\end{array}$ & F_prob \\
\hline Total & 149 & 120248993 & 807040 & $*$ & $*$ \\
\hline Treatments & 49 & 79415660 & 1620728 & 3.97 & 0.00000 \\
\hline Genotypes & 24 & 52259398 & 2177475 & 5.34 & 0.00000 \\
\hline Environments & 1 & 12103134 & 12103134 & 28.73 & 0.00000 \\
\hline Block & 4 & 1685176 & 421294 & 1.03 & 0.39426 \\
\hline Interactions & 24 & 15053128 & 627214 & 1.54 & 0.07387 \\
\hline IPCA & 24 & 15053128 & 627214 & 1.54 & 0.07387 \\
\hline Residuals & 0 & 0 & $*$ & $*$ & $*$ \\
\hline Error & 96 & 39148157 & 407793 & $*$ & $*$ \\
\hline
\end{tabular}

df, degrees of freedom; **, p $<0.01$; G, Genotypes; E, Environments.

The high addition of environment effects showed that there were important differences between growing season for grain yield. The results of AMMI analysis showed similar results of Kendal and Dogan(2015) and Yan and Rajcan (2002), reported that the environment effect had the highest effect than other factors on barley and soybean grain yield respectively.

The results of Environment, Genotype and G x E effects obtained from this study illustrated similar results of the studies described above and the effect of environment >genotypes > GEI. 
The existence interaction of grain yield displayed by GGE biplot, especially when the interaction portioned between two-interaction principal component axis (PCA) (Table 2). This status of GGE biplot made it establish and the biplot calculate effects of genotype and environment. The results of mean square of the interaction axis PCA 1 was significant $(\mathrm{p}<0.01)$, while PCA 2 was not significant. (Kendal 2015, Kilic 2014). Results of GGE biplot analysis also indicated that the PCA 1 axis accounted 78.58\%, PCA2 accounted for $21.42 \%$ (Fig. 3). GGE biplot showed existence interactions of $\mathrm{G} x \mathrm{E}$, so it was portioned between first and second IPCA (Interaction Principal Component Axes).

The barley grain yield variation is depending on genotypic and environment factors as shown Table 1 and Fig 1. Gauch \& Zobel (1997), Kendal and Dogan(2015), suggested that the AMMI model is the most accurate a model because it can predict using the first two IPCAs.

The closer the IPCAs scores to zero are meaning that genotypes are the most stable across their environments. Actually, these biplots is removed two types, model of AMMI 1 and model of GGE biplot (Carbonell et al 2004). In AMMI 1, the genotype and environments means are plotted on coordinate, the IPCA scores of same genotypes and environments, which are on the ordinate.

For interpretation of AMMI, size and signal scores of the IPCA1 were observed, score near to zero were typical of genotypes and environments, which contribute little to the interaction that is they are stable (Tarakanovas and Ruzgas 2006).

The AMMI model showing genotype $\mathrm{x}$ environment means of grain yield: In the AMMI model, $\mathrm{x}$-axis represents the genotypes and environment main effect and y axis represents the effects of interaction (Fig. 2). The environment and genotypes indicated much more variability in both main effect and interaction. According to AMMI, majority of genotypes (G4, G9, G10, G12, G13, G14, G16, G18, G24, G25) showed good performance, because of they took place above on axis (mean yield). It is believed that these genotypes were high yielding and desirable.

On the other hand, G1, G2, G3, G15, G6, G7, G21 demonstrated low performance, due to they located under on axis (mean yield). So, these cultivars and environments, which located under on axis (mean yield) were low yielding and undesirable. Moreover, 2005-06 growing season had both high yield potential and positive IPCA1 scores; it means that this growing season is desirable, because of high rainfall. While G16 and G25 had highest grain yield amongst genotypes, G12, G16 was very stable with low and positive IPCA scores (Table 4). According to Mirosavlievic et al (2014), the genotypes have small IPCA1 values are more stable, Becker \& Leon (1988) the basic static concept of stability shows minimal variance of stable genotype across different environments. Therefore, G17 can be recommended to all environments, while G8 and G23 for high yield potential environments (special environment). Similar outputs were recorded by Mohammadi et al (2013), in barley. 
Table 3. The average yield performance of genotypes at two growing seasons $\left(\mathrm{kg} \mathrm{ha}^{-1}\right)$

\begin{tabular}{|c|c|c|c|c|c|c|c|}
\hline Genotype & \multicolumn{2}{|c|}{$2004-05$} & \multicolumn{2}{|c|}{$2005-06$} & \multicolumn{2}{|c|}{ Mean } & IPCAg[1] \\
\hline 1 & 4417 & aj & 6283 & cg & 5350 & HK & -1.940 .078 \\
\hline 2 & 5172 & aj & 4914 & Ij & 5043 & IK & 1.234 .731 \\
\hline 3 & 5731 & af & 5544 & Ej & 5638 & DI & 1.126 .829 \\
\hline 4 & 5608 & ag & 5972 & C1 & 5790 & DH & 305.114 \\
\hline 5 & 5517 & ah & 5603 & Ej & 5475 & EJ & 973.276 \\
\hline 6 & 4942 & aj & 5433 & Fj & 5272 & HK & -138.945 \\
\hline 7 & 4661 & aj & 5817 & C1 & 5239 & HK & -877.658 \\
\hline 8 & 6081 & ad & 7667 & A & 6874 & AB & -1.520 .920 \\
\hline 9 & 5336 & aj & 6225 & cg & 5781 & DH & -479.251 \\
\hline 10 & 6017 & ae & 5664 & Dj & 5840 & DH & 1.375 .833 \\
\hline 11 & 6297 & ac & 7792 & A & 7044 & A & -1.383 .968 \\
\hline 12 & 5747 & af & 6506 & Cf & 6126 & CG & -284.197 \\
\hline 13 & 5689 & af & 6636 & Be & 6163 & BF & -566.402 \\
\hline 14 & 5525 & ah & 6217 & cg & 5871 & DH & -184.595 \\
\hline 15 & 4608 & aj & 4686 & J & 4647 & K & 732.572 \\
\hline 16 & 5672 & af & 6919 & Ac & 6296 & BD & -1.014 .611 \\
\hline 17 & 5106 & aj & 6228 & cg & 5667 & DI & -827.857 \\
\hline 18 & 6094 & ad & 6267 & cg & 6181 & BE & 591.469 \\
\hline 19 & 4517 & aj & 5064 & Hj & 4790 & JK & 0.31209 \\
\hline 20 & 6647 & a & 6733 & Ad & 6690 & AC & 720.121 \\
\hline 21 & 5053 & aj & 5483 & Fj & 5268 & HK & 205.512 \\
\hline 22 & 5369 & aj & 5514 & Fj & 5442 & FJ & 632.970 \\
\hline 23 & 5433 & a1 & 5378 & Gj & 5406 & GJ & 931.775 \\
\hline 24 & 5300 & aj & 6531 & Cf & 5915 & DH & -989.710 \\
\hline 25 & 6381 & ab & 6047 & Ch & 6214 & BD & 1.346 .783 \\
\hline Mean & 5477 & B & 6044 & A & & & \\
\hline CV(\%) & 10.0 & & 11.2 & & & & \\
\hline LSD & $97.0 * *$ & & $111.9 * *$ & & & & \\
\hline
\end{tabular}

Mega environments "which-won-where" pattern to identify the best genotypes in each environment: Dividing the target environment into meaningful mega-environments and deploying different cultivars for different megaenvironments is the only way to utilize positive GE and avoid negative GE and the sole purpose for genotype by environment interaction analysis (Yan et al 2000).

A mega-environment is defined as a group of environments that consistently share the same best cultivar(s) (Yan and Rajcan 2002). This definition explain the following biplot based on the multi-environment trials (MET) data of barley yield illustrates two points: 1) A mega-environment may have more than one winning genotypes (sector 2), and 2) even if there exists a 
universal winner (G12, G14), it is still possible, and beneficial, to divide the target environments into meaningful mega-environments (Fig. 3).

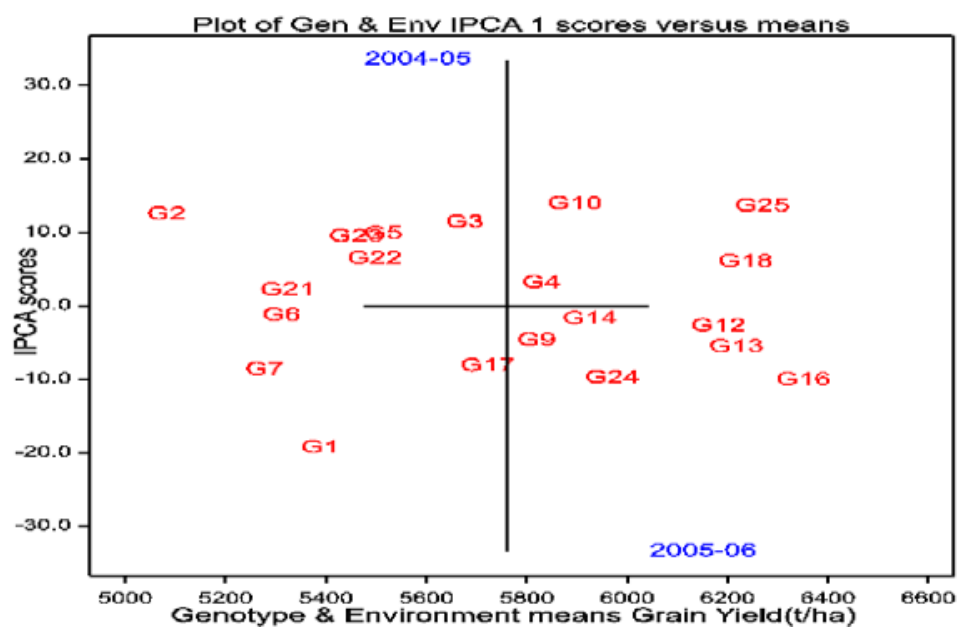

Fig. 2. The AMMI 1 model showing grain yield (kg/ha-1) of genotypes and growing seasons.

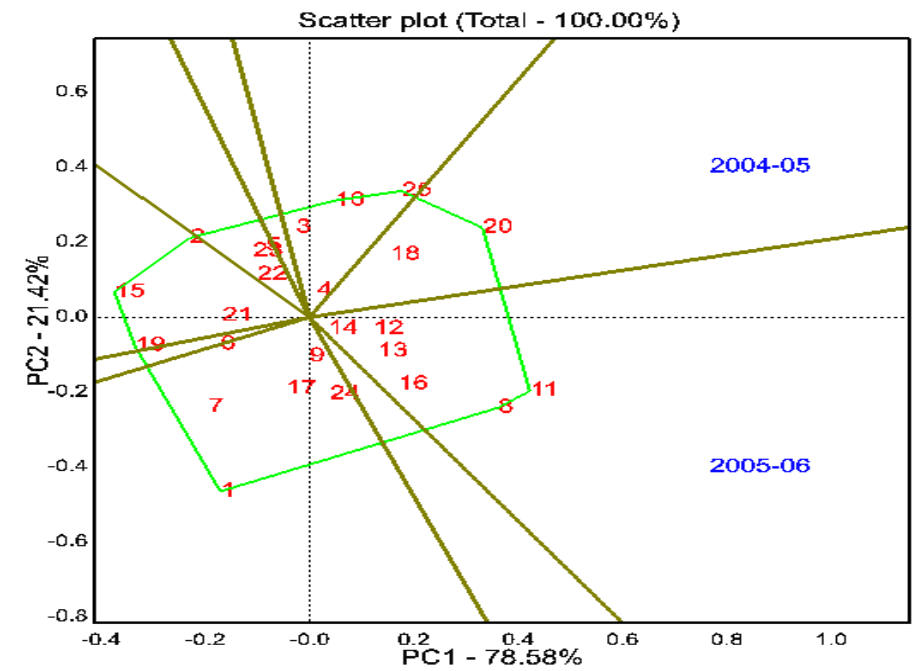

Fig. 3. Which genotype performed better in which environment for grain yield of barley

Mainly, these eight lines divide the biplot into eight sectors. The growing seasons located in different sectors; this means that the growing seasons had different ecological conditions. On the other hand, first sector consist of G11, G6 G23, G25 and G23 was high yielding and represented of vertex the 2005-06 growing season. The second sector consists of 2004-05 season with G18, G20, took places of vertex of this sector. The other sector just consists of some 
genotypes, which are not related with study growing season. Consequently, G11 had high yielding at 2005-06 growing season; while G20 for 2004-05. The result of this study showed that G11 is suitable to recommend to high potential growing season, while G20 for low potential growing season. Solonechnyi et al (2015), reported that there is a strong correlations between growing seasons, which located in same sector. Sarkar et al (2014), the large variation due to location indicated strong influence of environments and existence of mega-environment among trial conducting locations, this suggests the usefulness of GGE biplot technique for identifying mega- environments among barley growing locations. Mortazavian et al (2014), reported that the GGE biplot graphic analysis complements the AMMI biplot stratification, defining mega-environments and the cultivars that optimize performance in such mega-environments.

The GGE Biplot Analysis of genotypes by traits: In this analysis, the results of traits(Table 4) were examined by GGE Biplot analysis using different figures. The biplot of the principal component analysis illustrates relationships between the studied barley traits and genotypes at five environments (Figure 4Figure 7). First PCA explained $29.85 \%$ of total variation, while second PCA explained $22.29 \%$. Together, both axes accounted for $52.14 \%$ of the total variation in the data. According to the biplot figures, the relations between genotype and traits by traits were examined. The GGE Biplot showed that the breeders could select best genotypes for all traits and specific genotype for specific trait in breeding program.

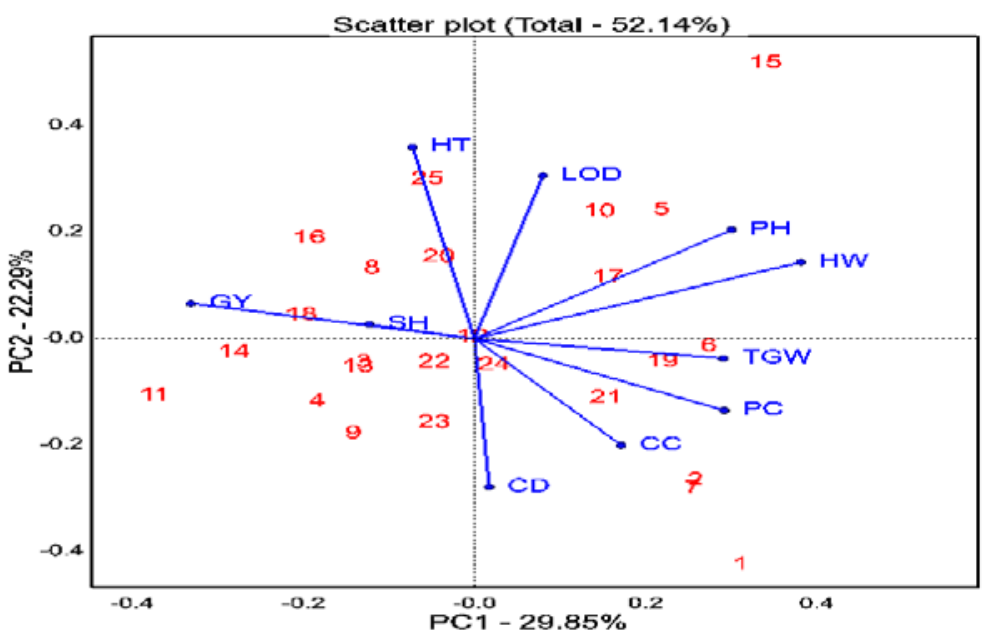

Fig. 4. The relationship genotype by trait in five environments

Therefore, the results of traits showed that there is high variation among genotypes. According to results, G11, G14 and G18 are desirable for GY, G6 and G19 are desirable for quality, so they can be recommended for release. On the other hands, all standarts(G5, G10, G15, G20 and G25) and G8 ,G16 had been late maturity time, very tall and lodging scores, so these genotypes is not 
recommend for growing season. The genotypes which located near to the biplot center(G20) have less contribution to G or GE, while genotypes having longer vectors show the most contribution of $G$ and/or GE (Yan and Tinker 2006). When the angle between two genotypes is $>90^{\circ}$, then this two genotype are different as genetic. So, G11 with the longest vectors is the best genotypes for grain yield, while G6 for TGW and PC. The genotypes are far from center of Biplot graphs, are specific genotypes(G1, G15 and G11) for specific trait.

Table 4. The traits value of average of 25 genotypes across 5 environment.

\begin{tabular}{|c|c|c|c|c|c|c|c|c|c|c|}
\hline $\begin{array}{c}\text { Genot } \\
\text { ypes }\end{array}$ & 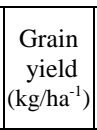 & $\begin{array}{c}\text { Heading } \\
\text { time } \\
\text { (date) }\end{array}$ & $\begin{array}{l}\text { Plant } \\
\text { height } \\
(\mathrm{cm})\end{array}$ & $\begin{array}{l}\text { Thousand } \\
\text { grain weigh } \\
\text { (g) }\end{array}$ & $\begin{array}{c}\text { Hectoliter } \\
\text { weight } \\
(\mathrm{g} / \mathrm{l})\end{array}$ & $\begin{array}{c}\text { Protein } \\
\text { content } \\
(\%)\end{array}$ & $\begin{array}{c}\text { Crude } \\
\text { cellulose } \\
(\%)\end{array}$ & $\begin{array}{c}\text { Seed } \\
\text { humidity } \\
(\%)\end{array}$ & $\begin{array}{c}\text { Lodging } \\
\text { (\%) }\end{array}$ & \begin{tabular}{|c|} 
Cold \\
damage \\
(Scor.1- \\
$9)$ \\
\end{tabular} \\
\hline 1 & 5350 & 104 & 98 & 47.5 & 73 & 12.3 & 6.05 & 8.4 & 0 & 6 \\
\hline 2 & 5043 & 103 & 95 & 49.6 & 72 & 12.7 & 6.10 & 8.5 & 20 & 7 \\
\hline 3 & 5638 & 110 & 88 & 43.1 & 65 & 11.1 & 5.45 & 8.6 & 30 & 5 \\
\hline 4 & 5790 & 110 & 85 & 41.0 & 63 & 11.6 & 5.55 & 8.6 & 30 & 6 \\
\hline 5 & 5560 & 118 & 103 & 47.6 & 75 & 12.4 & 5.95 & 8.7 & 30 & 3 \\
\hline 6 & 5188 & 113 & 105 & 40.3 & 73 & 12.7 & 5.35 & 2.8 & 20 & 7 \\
\hline 7 & 5239 & 104 & 95 & 50.6 & 73 & 12.9 & 5.85 & 8.3 & 0 & 6 \\
\hline 8 & 6874 & 118 & 100 & 39.9 & 70 & 11.6 & 5.45 & 8.6 & 20 & 7 \\
\hline 9 & 5781 & 120 & 95 & 34.5 & 65 & 12.1 & 5.60 & 8.4 & 0 & 7 \\
\hline 10 & 5840 & 118 & 105 & 44.5 & 75 & 11.9 & 5.55 & 8.5 & 20 & 4 \\
\hline 11 & 7044 & 112 & 88 & 35.0 & 61 & 11.6 & 5.55 & 8.5 & 0 & 5 \\
\hline 12 & 6126 & 113 & 98 & 42.8 & 70 & 12.2 & 5.00 & 8.6 & 2 & 5 \\
\hline 13 & 6163 & 110 & 95 & 40.0 & 68 & 11.0 & 5.60 & 8.5 & 0 & 5 \\
\hline 14 & 5871 & 120 & 88 & 39.3 & 63 & 10.2 & 5.70 & 8.7 & 0 & 2 \\
\hline 15 & 4647 & 117 & 110 & 42.3 & 76 & 12.5 & 5.60 & 8.6 & 80 & 0 \\
\hline 16 & 6296 & 112 & 95 & 36.1 & 66 & 11.1 & 5.45 & 8.7 & 60 & 4 \\
\hline 17 & 5667 & 110 & 103 & 43.8 & 73 & 12.2 & 5.75 & 8.8 & 30 & 3 \\
\hline 18 & 6181 & 113 & 95 & 37.8 & 66 & 11.1 & 4.75 & 8.6 & 0 & 4 \\
\hline 19 & 4790 & 105 & 110 & 38.4 & 74 & 11.8 & 6.05 & 8.8 & 0 & 4 \\
\hline 20 & 6690 & 111 & 105 & 42.1 & 74 & 10.7 & 5.15 & 8.8 & 0 & 3 \\
\hline 21 & 5268 & 108 & 103 & 40.1 & 71 & 12.6 & 6.15 & 8.5 & 0 & 5 \\
\hline 22 & 5442 & 110 & 93 & 38.1 & 65 & 12.8 & 5.35 & 8.5 & 0 & 1 \\
\hline 23 & 5406 & 107 & 93 & 38.1 & 65 & 12.4 & 6.10 & 8.9 & 0 & 3 \\
\hline 24 & 5915 & 109 & 103 & 38.8 & 71 & 12.0 & 5.60 & 8.8 & 0 & 5 \\
\hline 25 & 6214 & 113 & 98 & 44.0 & 71 & 10.3 & 6.10 & 8.6 & 50 & 1 \\
\hline Mean & 5457 & 111 & 96 & 39.7 & 63.2 & 12.3 & 4.9 & 10.7 & 28.5 & 3.9 \\
\hline
\end{tabular}

There are negative correlation between two traits, are opposite to each other(GY-TGW, HT-CD) on graph and the angles of vector is $>90^{\circ}$. Therefore, there is major contribution of trait to traits; because of they have opposite direction, so they can make up different genetic contribution (Jalata 2011).

"Which-won-where" pattern to identify the best genotypes for traits:The GGE biplot visualize the correlation amongs tratits and grouping them also to visualize the interaction patterns between genotypes and traits (Yan and Tinker 2006). Visualization of the "which won where" pattern of MET data is necessary for studying the possible existence of different more traits in the target traits ( Yan et al. 2000). Fig. 5 represents a polygon view of barley genotype MET data in this investigation. In this biplot, a polygon was formed by connecting the vertex genotypes with straight lines and the rest of the genotypes placed within 
the polygon. The partitioning of GT interaction divided into three group. The traits(TGW,PC, CC and CD)took place in first group and related with G6, G19, G21, G2 and G7; HT, LOD, PH and HW in second group and related with G5, G10 and G25; GY and SH in thirth group and related with G13 and G14.Other genotypes did not related with any group of tratis. On the other hand, there were correlation amongs tratis which took places in same group. it means that the genotypes, have late heading time, are very tall and have lodging features as well as. The vertex genotypes in this study were G1, G15 and G11. These genotypes were the best for special traits or the poorest genotypes some for all of traits because they were farthest from the origin of the biplot(Yan and Kang 2003).

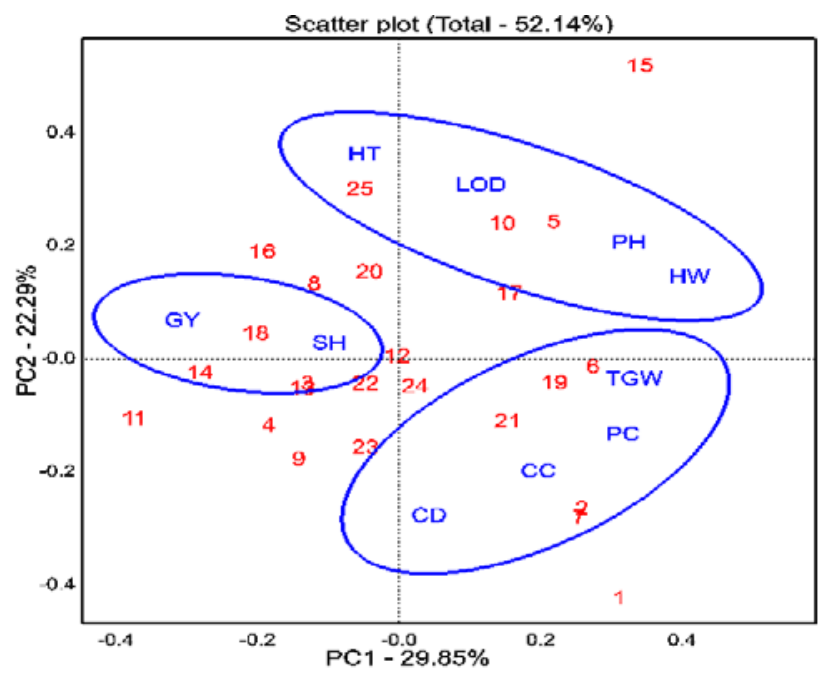

Fig. 5. Gge biplot showing the performance of each cultivar at each environment.

Ranking genotypes based on traits mean and instability: the genotype has both high traits mean and high stability is called a favorable genotype. It should have both high mean performance and high stability for all traits (fig. 6). The center of the concentric circles (ideal) is a point on the aea("absolutely stable") in the positive direction and has a vector length equal to the longest vectors of the traits on the positive side of aea ("highest mean performance"). Therefore, genotypes located closer to the stabile line and has high mean values of traits are meaning that it is more favorable than others (yan and tinker, 2006; farshadfar et al 2013.thus, g17 is located center of aea ("absolutely stable"), but; g5, g6 and g15 took place of near center of aea and high mean of traits. So these genotypes are favorable than others. According to fig.5, the g15, g5 and g6 are low stable and more favorable, while g17 are "stable" and favorable, because this genotype has high mean value of traits. From this example, we can recommend g17 and g5 to study for more traits. On the other hand, some genotypes (g11, g14, g4, g9, g18, g13, g16, g23, g8 and g22) were unfavorable, because these genotypes had low mean values of traits. 


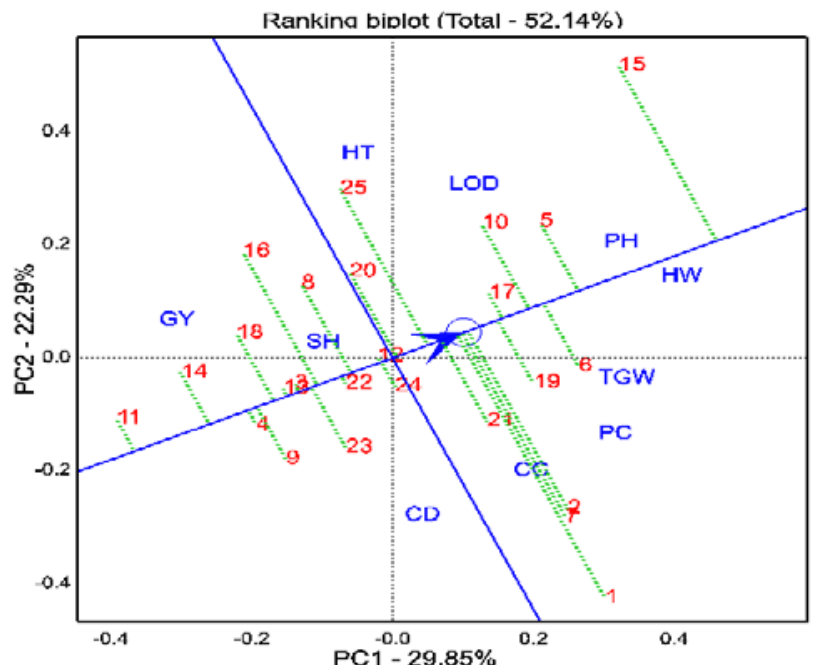

Fig. 6. Ranking genotypes based on traits mean and instability

Comparison of genotypes based on traits by ideal genotype: the genotype has both high traits mean and high stability is called a ideal genotype (fig. 7).

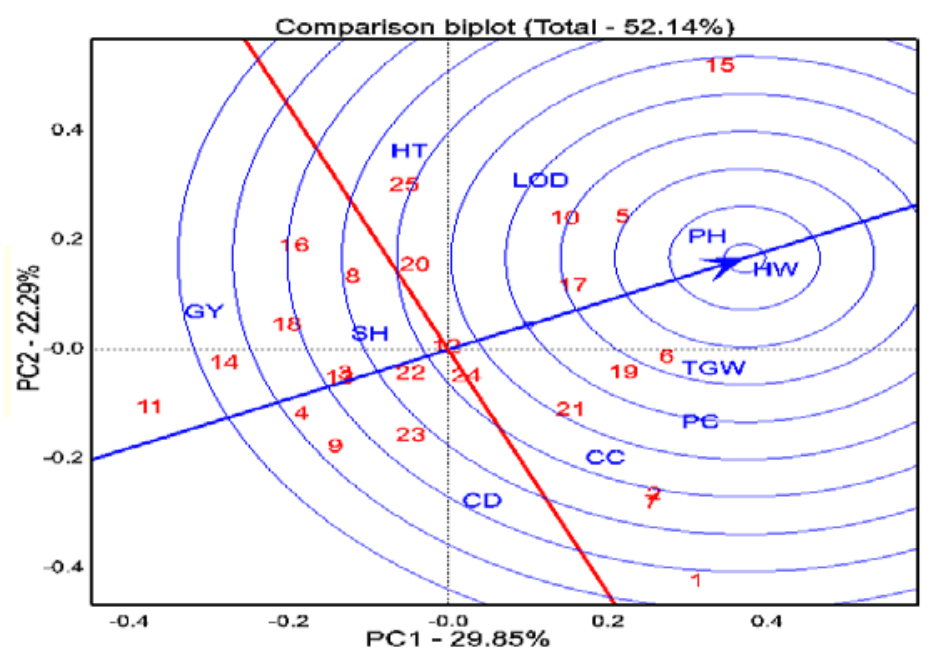

Fig. 7. The relationship genotype by trait in two seasons

The center of the concentric circles is a point on the aea ("absolutely ideal") in the positive direction and has a vector length equal to the longest vectors of the traits on the positive side of AEA ("highest mean performance"). So, genotypes located closer to the ideal circle are meaning that it is ideal genotype than others (Yan and Tinker, 2006). In the study, any genotype was not located center of AEA ("absolutely stable”), but; G5, G6 and G17 took place of near center of AEA. So these genotypes are ideal than other genotypes. 
Consequently, G6 and G17 are close to ideal genotype, so, these genotypes can be recommended for release in terms of all traits.

On the other hand, more genotypes located far from ideal genotype and, these genotypes (g11, g14, g4, g9, g18, g13, g16, g23, g8 and g22) are not ideal genotypes to study and release. The researchers reported that the biplot show excellent discriminating to select genotypes for all traits and to recommendation for release (sayar and han, 2015).

\section{CONCLUSIONS}

The GGE Biplot and AMMI results indicated that yield performance of barley genotypes were highly influenced by growing season conditions (rainfall, hot stress). The genotype G12, G13, G16 and G18 demonstrated best performance among genotypes tested growing seasons, while G2 had least grain yield and adaptability. Therefore, the G16 was desirable in terms of high mean yield and stability; this means that the study provided an indication of the genetic progress. According to the results, the specific genotypes were appropriate for specific traits (G6, G19 and G21 for quality, G14 and G18 for GY, G2 and G7 resistance to cold damage). The AMMI method and GGE Biplot analysis permitted a meaningful and useful summary of GE interaction data and assisted in examining the natural relationships and variations in genotype performance across test growing seasons. As a result indicated that that G12 and G16 are suitable to recommend for release and G6, G19 and G21 valuable source for quality to use in barley breeding program.

\section{ABBREVITATIONS}

AMMI, Additive main effects and multiplicative interaction; AEA, average-environment axis; AEC, average-environment coordination; GE, genotype by environment interaction; GGE, G + GE; MET, multi-environment trials; PC, principal component; PCA, principal component analysis; E, environment; G, genotype; TGW, thousand grain yield; HW, hectoliter weight; PC, protein content; SA, sieving above; LS, lower sieving.

\section{REFERENCES}

Asfaw, A., Alemayehu, F., Gurum, F., Atnaf, M. (2009).AMMI and SREG GGE biplot analysis for matching varieties onto soybean production environments in Ethiopia, Scientific Research and Essay Vol. 4(11) pp. 1322-1330.

Becker, H.C. and Leon, J.(1998). Stability analysis in plant breeding, Plant Breed, 101:123.

Carbonell, S. A., Filho, J.A., Dias, L.A., Garcia, A.A and Morais L.K.(2004) Common bean cultivars and lines interactions with environments. Sci. Agric (Pracicaba Braz) 61(2):169-177.

Farshadfar, E., Rashidi, M, Jowkar M.M. and Zali, H. (1971).GGE Biplot analysis of genotype $\times$ environment interaction in chickpea genotypes, European J. of Exper. Biology, 3(1):417-423.

Gabriel, K.R. (1971. The biplot graphic display of matrices with application to principal component analysis, Biometrika 58: 453-467. 
Gauch, H.G. and Zobel, R.W (1997). Identifying mega-environments and targeting genotypes. Crop. 37:311-326.

Gauch, H.G. (2013). Model selection and validation for yield trials with interaction”, Biometrics 44,705-715, 1988.

Hagos, G. H. and Abay, F. (2013). AMMI and GGE Biplot analysis of bread wheat genotypes in the northern part of Ethiopia. Journal Plant Breeding and Genetic. $01: 12.18$,

Jalata, Z. (2011).GGE-biplot Analysis of Multi-environment yield trials of barley(Hordeum vulgare L.) genotypes in Southeastern Ethiopia Highlands. International J.of P. Breeding and Gen. 5(1):59-75.

Kendal, E. (2015). Determination of relationship between chlorophyll and other features in durum Wheat (Triticum turgidum L. var. durum) using SPAD and biplot analyses. Journal of Agricultural and Technology, Vol. 17(supplementary Issue)1873-1886.

Kendal, E. (2016). GGE Biplot analysis of Multi-environment Yield Trials in Barley (Hordeum vulgare L) Cultivars. Ekin J. of Crop Breeding and Genetics, (2016) 23:90-99.

Kendal, E and Dogan, Y. (2015). Stability of a Candidate and Cultivars (Hordeum vulgare L) .by GGE Biplot analysis of Multi-environment Yield Trials in Spring Barley. Agriculture \& Forestry, Vol. 61, Issue 4: 307-318, 2015, Podgorica, DOI: 10.17707/Agricult Forest. 61.4.37.

Kendal, E and Sener, O. (2015). Examination of genotype $\times$ environment interactions by GGE biplot analysis in spring durum wheat. Indian Journal of Genetics and Plant Breeding, 75(3): 341-348 (2015), DOI: 10.5958/0975-6906.2015.00054.1.

Kilic, H.(2014). Additive main effect and multiplicative interactions (AMMI) Analysis of grain yield in barley genotypes across environments. J. Agr. Sc. 20,337-344.

Mirosavlievic, M., Przulj, N., Bocanski, N., Stanisavlievic, D., Mitrovic, B. (2014). The application of AMMI model for barley cultivars evaluation in multi-year trials. Genetika, Vol: 46, No. 2, 445-454.

Mirosavlievic, M. N., Przuli, N. and Canak, P. (2014). Analysis of new experimental barley genotype performance for grain yield using AMMI Biplot. Selekcija I Semenarstvo, Vol: broj 1 ..

Mirosavlievic, M. N. Przuli, N. and Canak, P. Momcilovic, V. Aćin V., Jocković, B. Hristov, N. Mladenov, N. (2015). Relationship between Grain Yield and Agronomic Traits in Winter Barley. IFVC, doi:10.5937/ratpov52-7860.

Mohammadi, M., Karimizadeh, R., Noorinia, A A., Ghojogh, H. Hosseinpour, T., Khalilzadeh, GR., Mehraban, A., Roustaii, M. Hasanpor Hosni M. (2013). Analysis of yield stability in multi-environment trials of barley (Hordeum vulgare L.) genotypes using AMMI model. Current Opinion in Agriculture Curr. Opin. Agric. 2(1), 20-24.

Mortazavian, S. M. M., Nikkhah, H. R., Hassani F. A., Sharif-al-Hosseini M. Taheri, M. and Mahlooji, M. (2014).GGE Biplot and AMMI Analysis of yield performance of barley genotypes across different environments in Iran. J. Agr. Sci. Tech. Vol. 16: 609-622.

Przuli, N., Momcilović, V., Simić, J. and Mirosavljević, M. (2014). Effect of growing season and variety on quality of spring two-rowed barley. Genetika, 46: 59-73,

Rahmatollah, K., Mohtasham, M., Naser, S., Ali, A.M., Barzo, R., Faramarz, S., Fariba, A. (2013).GGE Biplot analysis of yield stability in multi-nvironment trials of lentil genotypes under rainfed Condition. Not Sci Biol, 5(2):256-262. 
Sarkar, B., Sharma, R.. C. R, Verma Ananta Sarkar P. S. and Sharma, I. (2014). Identifying superior feed barley genotypes using GGE biplot for diverse environments in India. Indian J. Genet., 74(1): 26-33 (2014) DOI: 10.5958/j.0975-6906.74.1.004.

Solonechnyi, P., Vasko, N., Naumov, A., Solonechnaya, O., Vazhenına, O., Bondareva, O., Lovnivenko, Y. 2015. GGE biplot analysis of genotype by environment interaction of spring barley varieties. Zemdirbyste-Agri., vol. 102, 431-436.

Sayar, M.S. and Han, Y. (2015).Determination of seed yield and yield components of grasspea (Lathyrus sativus L.) lines and evaluations using GGE Biplot analysis method. Tarim Bilimleri Dergisi- J. Agric. Sci,, 21(1): 78-92.

Tarakanovas, P and Ruzgas, V. (2006).Additive main effect and multiplicative interaction analysis of grain yield of wheat varieties in Lithuania. Agr. Research. 4(1):91-98.

Yan, W. L., Hunt, A. Sheng, Q. and Szlavnics, Z. (2000). Cultivar evaluation and megaenvironment investigation based on the GGE biplot. Crop Sci. 40: 597-605.

Yan, W. and Rajcanw, I. (2002). Biplot analysis of test sites and trait relations of soybean in Ontario. Crop Science 42. 11-20.

Yan, W., Kang MS. (2003). GGE Biplot Analysis: A graphical tool for breeders, geneticists, and agronomists. CRC Press, Boca Raton, p 213.

Yan, W. and Tinker, N.A. (2006). Biplot analysis of multi-environment trial data; Principles and applications”, Canadian Journal of Plant Science 86, 623-645.

Yan, W and Holland, J.B. (2010). A heritability adjusted GGE biplot for test environment evaluation Euphytica, 171(3): 355-369. 